Cochrane Database of Systematic Reviews

\title{
Antiepileptic drugs for the primary and secondary prevention of seizures after intracranial venous thrombosis (Review)
}

Price M, Günther A, Kwan JSK

Price M, Günther A, Kwan JSK.

Antiepileptic drugs for the primary and secondary prevention of seizures after intracranial venous thrombosis.

Cochrane Database of Systematic Reviews 2016, Issue 4. Art. No.: CD005501.

DOI: 10.1002/14651858.CD005501.pub4.

www.cochranelibrary.com

Antiepileptic drugs for the primary and secondary prevention of seizures after intracranial venous thrombosis (Review) 
ABSTRACT 1

PLAIN LANGUAGE SUMMARY

BACKGROUND

OBJECTIVES

METHODS

RESULTS

DISCUSSION

AUTHORS' CONCLUSIONS

ACKNOWLEDGEMENTS

REFERENCES

APPENDICES

WHAT'S NEW

HISTORY

CONTRIBUTIONS OF AUTHORS

DECLARATIONS OF INTEREST

SOURCES OF SUPPORT

INDEX TERMS

\section{TABLE OF CONTENTS}


[Intervention Review]

\section{Antiepileptic drugs for the primary and secondary prevention of seizures after intracranial venous thrombosis}

Michelle Price ${ }^{1}$, Albrecht Günther2 ${ }^{2}$ Joseph SK Kwan³

1Royal Bournemouth Hospital, Bournemouth, UK. 2Department of Neurology, Jena University Hospital, Jena, Germany. ${ }^{3}$ Department of Medicine, The University of Hong Kong, Queen Mary Hospital, Hong Kong, China

Contact: Joseph SK Kwan, Department of Medicine, The University of Hong Kong, Queen Mary Hospital, 102 Pok Fu Lam Road, Hong Kong, China. jskkwan@hku.hk.

Editorial group: Cochrane Epilepsy Group.

Publication status and date: New search for studies and content updated (no change to conclusions), published in Issue 4, 2016.

Citation: Price M, Günther A, Kwan JSK. Antiepileptic drugs for the primary and secondary prevention of seizures after intracranial venous thrombosis. Cochrane Database of Systematic Reviews 2016, Issue 4. Art. No.: CD005501. DOI: 10.1002/14651858.CD005501.pub4.

Copyright (c) 2016 The Cochrane Collaboration. Published by John Wiley \& Sons, Ltd.

\section{A B S T R A C T}

\section{Background}

Intracranial venous thrombosis (ICVT) commonly presents with seizures in the acute period, and some people may develop recurrent seizures in the long term. The prophylactic use of antiepileptic drugs (AEDs) for the management of post-ICVT seizures is controversial, and there is currently no consensus on the optimal management of post-ICVT seizures. This is an updated version of the Cochrane review first published in theCochrane Database of Systematic Reviews 2006, Issue 3.

\section{Objectives}

To assess the effects of AEDs for the primary and secondary prevention of seizures related to ICVT.

(1) For the question of primary prevention, we aimed to examine whether AEDs reduce the likelihood of seizures in people who have had an ICVT but have not had a seizure.

(2) For the question of secondary prevention, we aimed to examine whether AEDs reduce the likelihood of further seizures in people who have had an ICVT and at least one seizure.

\section{Search methods}

For the latest update, we searched the Cochrane Epilepsy Group Specialized Register, the Cochrane Central Register of Controlled Trials (CENTRAL) via the Cochrane Register of Studies Online (CRSO), and MEDLINE (Ovid 1946 onwards) to 20 April 2015, and we checked the reference lists of articles retrieved from the searches.

\section{Selection criteria}

We planned to include all randomised and quasi-randomised controlled trials in which participants with a diagnosis of ICVT were assigned to a treatment group (that is, receiving at least one AED) or control group (receiving placebo or no drug).

\section{Data collection and analysis}

Both review authors independently screened and assessed the methodological quality of the studies. If studies had been included in the review, one review author would have extracted the data and another would have checked the extracted data.

\section{Main results}

No relevant studies were found. 


\section{Authors' conclusions}

There is no evidence to support or refute the use of antiepileptic drugs for the primary or secondary prevention of seizures related to intracranial venous thrombosis. Well-designed randomised controlled trials are urgently needed to inform practice. Since the last version of this review no new studies have been found.

\section{PLAIN LANGUAGE SUMMARY}

Antiepileptic drugs for the primary and secondary prevention of seizures after intracranial venous thrombosis (ICVT)

\section{Review question}

We reviewed the evidence around the use of antiepileptic medication to prevent seizures after intracranial venous thrombosis.

\section{Background}

Intracranial venous thrombosis is caused by blood clots in a vein or venous sinus in the brain. This can result in seizure activity. It remains unclear which people with intracranial venous thrombosis should receive antiepileptic drugs as a preventative treatment. We wanted to clarify the potential benefit balanced with the potential side effects of using antiepileptic medication in this group of people.

\section{Study characteristics}

No study up to April 2015 met the inclusion criteria for review.

\section{Key results}

There is currently no evidence from randomised controlled trials to support or refute the use of antiepileptic drugs for the prevention of seizures related to intracranial venous thrombosis. 


\section{B A C K G R O U N D}

\section{Description of the condition}

Intracranial venous thrombosis (ICVT) is the obstruction of one or more of the cerebral veins or venous sinuses, which causes a rise of venous pressure in its drainage territory (that is, venous hypertension) leading to venous engorgement and brain oedema (Arquizan 2002). This can lead to reduced blood flow in the region. The affected cerebral cortex and underlying white matter may become congested, swollen and haemorrhagic, leading to venous infarction (Arquizan 2002).

ICVT was first described by Ribes in 1825 . At that time the condition was largely regarded as fatal, with the majority of diagnoses being made at post-mortem (Benamer 2000). More recently, the diagnosis of ICVT has become easier to confirm with new and less invasive neuroimaging techniques such as magnetic resonance imaging (MRI) (Connor 2002). This has resulted in early treatment and thus much better prognosis than was previously thought possible. In the International Study on Cerebral Vein and Dural Sinus Thrombosis, the 30-day case fatality rate was only $3.4 \%$, and the median time from onset to death was 13 days (Canhão 2005a). Another prospective study found that at six months after ICVT 16\% of participants had died, $7 \%$ were dependent for daily activities, and $77 \%$ were independent (Stolz 2005). Treatments of ICVT with anticoagulation, thrombolysis, and corticosteroids have been subjects of a couple of Cochrane reviews (Ciccone 2004; Coutinho 2011).

The exact frequency of ICVT in the general population is unclear (Arquizan 2002). Nevertheless, it is relatively rare and accounts for less than $1 \%$ of all strokes (Masuhr 2004). ICVT can occur in all age groups, with the highest incidence being amongst neonates and adults in their third decade. ICVT is more common amongst females (male/female ratio of 1.5 to 5). Due to the wide spectrum of clinical symptoms and gradual onset of symptoms, the diagnosis is often missed or delayed. Important causes and predisposing factors include intracranial or systemic infections, coagulation disorders (for example protein $\mathrm{C}$ or $\mathrm{S}$ deficiency), vascular trauma (for example neurosurgery, head injury), space-occupying lesions (for example intracranial and extracranial malignancies), hormonal factors (for example the oral contraceptive pill, pregnancy, puerperium), vasculitis (for example lupus erythematosus, Behçet's disease), metabolic disorders (for example homocystinuria, hyperhomocysteinaemia), and others (for example following a lumbar puncture). However, in up to a third of people there may be no identifiable cause (Allroggen 2000; Canhão 2005b; Heller 2003; Masuhr 2004).

There are several key pathophysiological differences between arterial and venous thrombosis in the brain. Firstly, ICVT is widely regarded as a continuing process in which the balance of prothrombotic and thrombolytic processes is disturbed, leading to progression of the venous thrombus with time. This slow growth of the thrombus, together with good collateralisation of venous vessels, could explain why some people present with more gradual onset of symptoms, often over days or weeks. In one retrospective multicentre study of 48 participants $44 \%$ presented acutely, $35 \%$ presented subacutely, and $21 \%$ presented in a chronic state (Terazzi 2005). Secondly, haemorrhagic transformation occurs in a significant proportion of people, probably as a result of raised venous and capillary pressure at and around the site of occlusion (Allroggen 2000).

The clinical presentation of ICVT depends on the extent and site of venous occlusion, the progression of the thrombotic process, and the existence of venous collaterals (Masuhr 2004; Van den Bergh 2005). Occlusion of a large venous sinus may lead to more generalised neurological sequelae, such as intracranial hypertension, epileptic seizures, and altered consciousness, with a poorer outcome. Involvement of isolated cortical veins may present with more focal neurological symptoms such as motor or sensory deficits and focal seizures (Van den Bergh 2005). In some mild cases headache might be the only presenting feature (Cumurciuc 2005).

\section{Description of the intervention}

Compared with people with strokes caused by arterial occlusion, those with ICVT are much more likely to experience seizures at the initial presentation and during follow-up (Buccino 2003; De Bruijn 2001; Ferro 2003; Masuhr 2004). In one series of 59 participants with ICVT, 47\% experienced seizures on admission (De Bruijn 2001). In another series of 142 participants with ICVT, 34\% experienced seizures within the first two weeks of the event, and $10 \%$ experienced seizures after the first two weeks (Ferro 2003). In yet another series of 77 participants, $36 \%$ experienced seizures in the acute period (undefined) but only $5 \%$ developed recurrent seizures (Preter 1996). The frequency of seizures may be even higher amongst children with ICVT. In a series of 58 children with ICVT, 58\% experienced seizures on admission, and those presenting with seizures were more likely to have a bad outcome (DeVeber 2001). In Ferro 2003, early seizures were found to be more frequent in people with motor and sensory deficits and in those with computed tomography (CT) or MRI evidence of focal brain oedema, venous infarction, or intracerebral haemorrhage on admission. Furthermore, late seizures were more frequent in people with early seizures and CT or MRI evidence of haemorrhage. However, the relationship between post-ICVT seizures and outcome remains unclear; some studies have identified seizures as a poor prognostic indicator (Benamer 2000; DeVeber 2001; Stolz 2005) whilst others have not found such a relationship (Ferro 2003).

\section{How the intervention might work}

The prophylactic use of antiepileptic drugs (AEDs) for the management of post-ICVT seizures is controversial. In Ferro 2003, of the 31 participants who experienced early seizures after ICVT, $18(58 \%)$ were prescribed AEDs, and of the 60 participants who did not experience early seizures $12(20 \%)$ were prescribed AEDs. There is currently no consensus on the optimal management of post-ICVT seizures. Whilst some experts recommend prophylactic treatment with AEDs for all people with ICVT because of the high risk of seizures and their potential adverse physiological effects (Einhaupl 1994), others have more recently recommended reserving prophylactic treatment only for those who have already had a seizure, that is, for secondary prevention only (Buccino 2003; Masuhr 2004). On the other hand, Ferro 2003 was specific in recommending that prophylactic treatment should be used in those with proven risk factors for seizures (for example those who have already experienced seizures or who have CT or MRI evidence of haemorrhage). 


\section{Why it is important to do this review}

This is an update of a review in the Cochrane Database of Systematic Reviews first published in 2006 (Kwan 2006), which found no evidence to support or refute the use of AEDs for the primary or secondary prevention of seizures related to ICVT.

Overall, it remains unclear which people with ICVT should receive prophylactic AEDs and which drug should be used, at what dosage, and for how long (Masuhr 2004). Any potential benefits of using AEDs should also be balanced with their potential side effects. This systematic review aimed to review updated evidence to assess the potential benefits and risks of AEDs for the prevention of seizures related to ICVT.

\section{O B JECT IVES}

To assess the effects of antiepileptic drugs (AEDs) for the primary and secondary prevention of seizures related to intracranial venous thrombosis (ICVT).

1. For the question of primary prevention, we aimed to examine whether AEDs reduce the likelihood of seizures in people who have had an ICVT but have not had a seizure.

2. For the question of secondary prevention, we aimed to examine whether AEDs reduce the likelihood of further seizures in people who have had an ICVT and at least one seizure.

\section{METHODS}

\section{Criteria for considering studies for this review}

\section{Types of studies}

We considered all randomised and quasi-randomised controlled trials in which participants were assigned to a treatment group (that is, receiving at least one AED) or control group (that is, receiving placebo or no drug).

\section{Types of participants}

We considered all studies that had recruited participants with a diagnosis of ICVT (including cerebral venous thrombosis and dural sinus thrombosis), regardless of aetiology or method of diagnosis, and who had, or had not, experienced seizures postICVT. For studies which reported the results for a mixture of participant groups (for example arterial and venous thromboses) we attempted to separate them and identify those results which were relevant to the participant groups of interest. If this was not possible despite contacting the investigators, the studies were subjected to a sensitivity analysis to determine the effects of including and excluding the studies. Children or adults with generalised or focal seizures, or both, were included.

\section{Types of interventions}

AEDs included carbamazepine, clobazam, clonazepam, diazepam, ethosuximide, gabapentin, lamotrigine, levetiracetam, lorazepam, oxcarbazepine, phenytoin, phenobarbitone, primidone, sodium valproate, tiagabine, topiramate, vigabatrin, and zonisamide. We considered all trials in which the intervention was compared with a placebo or with no drug.

\section{Types of outcome measures}

\section{Primary outcomes}

The primary outcome was the proportion of participants who experienced clinical seizures in the scheduled follow-up period. In cases where seizures had occurred, their nature (generalised or focal), timing (early or late), and whether an electroencephalography had been performed were noted. The investigators were contacted if the outcome data were not readily available in the published report. As described in the Background, seizures occurring within the first week of ICVT were defined as early seizures, and those occurring after the first week were defined as late seizures (ILAE 1981). The occurrence of recurrent late seizures was defined as post-ICVT epilepsy.

\section{Secondary outcomes}

1. Proportion of participants who achieved remission for a predefined period of time (for example 12 or 24 months).

2. Proportion of participants who suffered status epilepticus.

3. Proportion of participants who withdrew from the allocated treatment within the scheduled follow-up period. This is a composite outcome which takes into account several factors including adverse events, compliance, and effectiveness of treatment. We were particularly interested in the occurrence of side effects for the different AEDs, which may be physical or neurobehavioural (for example problems with memory, attention, and performance skills).

4. Proportion of participants who were dead or dependent at the end of the scheduled follow-up period. 'Independent' individuals were to be defined as those who did not require regular physical assistance from another person for activities of daily living, such as mobility, dressing, transfers, and feeding. 'Dependent' individuals were to be those who failed to meet one or more of these criteria.

\section{Other outcomes of interest}

1. Quality of life (for example using a recognised scoring system such as SF36 and EuroQol).

2. Duration of hospital stay for the acute phase of recovery after ICVT.

3. 'Optimal' duration of treatment (that is, length of time that the intervention should be continued).

\section{Search methods for identification of studies}

Searches were run for the original review in October 2005, and subsequent searches were run in January 2010, August 2011, August 2013, and April 2015. For the latest update the following databases were searched:

1. Cochrane Epilepsy Group Specialized Register on 20 April 2015, using the search strategy outlined in Appendix 1.

2. Cochrane Central Register of Controlled Trials (CENTRAL) via the Cochrane Register of Studies Online (CRSO, 20 April 2015), using the search strategy outlined in Appendix 2.

3. MEDLINE (Ovid 1946 to 20 April 2015). The MEDLINE search strategy is outlined in Appendix 3.

Previously the Cochrane Stroke Group searched their specialized register for this review using the search strategy outlined in 
Appendix 4, but that is no longer necessary because any relevant studies in the Group's register are now included in CENTRAL.

We also checked the reference lists of articles retrieved from the above searches. Where clarification of information was needed, we attempted to contact the investigators of the relevant studies.

\section{Data collection and analysis}

\section{Selection of trials}

Two review authors (JK, MP) screened all of the titles, abstracts, and keywords of publications identified by the searches, to assess their eligibility. Publications that clearly did not meet the inclusion criteria were excluded at this stage. We obtained a paper copy of the full publication of every study that might possibly be relevant. Both review authors (JK, MP) assessed each one according to prespecified selection criteria (see Criteria for considering studies for this review). Any disagreement was resolved by discussion.

\section{Assessment of methodological quality}

If studies had been included, we would have independently assessed the methodological quality of the included studies and recorded the findings. We would have noted the important aspects of methodology: study design, type of control, method of allocation concealment, completeness of follow-up, and the presence of blinding for assessments of non-fatal outcomes.

\section{Data extraction}

If studies had been included, one review author (JK) would have extracted the data onto a data extraction form and another review author (AG) would have independently checked the extracted data. Data reported by the published sources would have been used for the analyses in this review. Where additional outcome data were needed, we would have attempted to contact the investigators of the studies. Apart from the methodology and outcome data, we also planned to extract demographic data (for example total number of participants randomised, number of participants per group, age and sex distribution) and possible confounding factors. These could have included certainty of diagnosis of ICVT, location and aetiology of venous thrombosis, severity of condition, presence of a venous infarct, previous history of epilepsy, other co-morbid disorders, method and duration of treatments such as anticoagulation, number of participants who withdrew from the study or were lost during follow-up, and duration of follow-up. Any disagreement would have been resolved by discussion and a consensus decision made.

\section{Data analysis}

If studies had been included, data analysis would have abided by the guidelines set out by The Cochrane Collaboration regarding statistical methods. Primary analysis would have been by intention-to-treat. For dichotomous data, we planned to express relative treatment effects as odds or risk ratios, as appropriate, with $95 \%$ confidence intervals. For continuous data, we planned to use mean differences with $95 \%$ confidence intervals. A P value of less than 0.05 would have been taken as statistically significant. Clinical heterogeneity would have been assessed by the distribution of demographic and prognostic variables across the treatment and control groups. Statistical heterogeneity between studies would have been assessed using the $1^{2}$ statistic and the $\mathrm{Q}$ test for heterogeneity. Where there was no significant clinical or statistical heterogeneity, and if it appeared sensible to combine the results, we planned to undertake a meta-analysis using a random-effects model.

\section{RE S U L T S}

\section{Description of studies}

\section{Results of the search}

No study met the inclusion criteria that were set out in this review. For the 2015 update, literature searches identified four articles. For the 2014 update, literature searches identified four articles. For the 2011 update, 17 articles were identified. None of the articles identified were of studies that assessed the effects of AEDs for the primary or secondary prevention of seizures related to ICVT. Hence, no data were available for extraction or analysis.

\section{Included studies}

No studies met the inclusion criteria.

\section{Excluded studies}

All potentially-relevant studies identified were excluded as they did not meet the criteria for this review.

\section{Risk of bias in included studies}

No relevant studies were found.

\section{Effects of interventions}

No data from relevant studies were available for analysis.

\section{DISCUSSION}

\section{Summary of main results}

We did not find any studies that assessed the effects of AEDs for the primary or secondary prevention of seizures related to ICVT.

Despite the relatively low incidence of ICVT, the clinical problem of post-ICVT seizures is still an important one. Previous observational studies have reported a high frequency of seizures following ICVT as well as a possible correlation with poor functional outcomes. There is currently no consensus on the optimal strategy to prevent post-ICVT seizures, and this systematic review has not found any evidence to support or refute the use of AEDs for this purpose. The balance between the relative benefits and risks of treatment with AEDs remains unclear.

\section{Overall completeness and applicability of evidence}

We did not find any studies that assessed the effects of AEDs for the primary or secondary prevention of seizures related to ICVT.

\section{Quality of the evidence}

Well-designed randomised controlled trials are needed to provide the necessary high-level evidence to effectively inform clinical practice. 


\section{AUTHORS' CONCLUSIONS}

\section{Implications for practice}

There is no evidence to support or refute the use of antiepileptic drugs for the primary or secondary prevention of seizures related to intracranial venous thrombosis. Since the last version of this review no new studies have been found.

\section{Implications for research}

No study has been conducted to evaluate the safety and effects of antiepileptic drugs for the primary or secondary prevention of seizures related to intracranial venous thrombosis. Well-designed randomised controlled trials are, therefore, urgently needed to inform clinical practice. Such clinical trials should consider assessing the following clinically-relevant outcomes as outlined in this systematic review:
- Proportion of participants who experience seizures (and status epilepticus) in the scheduled follow-up period.

- Proportion of participants who achieve remission for a predefined period of time.

- Proportion of participants who withdraw from the allocated treatment in the scheduled follow-up period, and the reasons for withdrawal.

- Proportion of participants who are dead or dependent at the end of the scheduled follow-up period.

- Quality of life.

- Duration of hospital stay.

- Optimal duration of treatment.

\section{ACK N O WLEDGEMENTS}

We are grateful to the Cochrane Epilepsy Group, Cochrane Stroke Group, the editors, our editorial mentor ( $\mathrm{Dr}$ Sridharan Ramaratnam) and other peer reviewers for their comments and advice in writing this review. 


\section{RE F E R E N C E S}

\section{Additional references}

\section{Allroggen 2000}

Allroggen $\mathrm{H}$, Abbot RJ. Cerebral venous sinus thrombosis. Postgraduate Medical Journal 2000;76(891):12-5.

\section{Arquizan 2002}

Arquizan C, Meder JF, Mas JL. Brain venous thrombosis syndromes. In: Bogousslavsky J, Caplan LR editor(s). Stroke Syndromes. Second Edition. Cambridge: Cambridge University Press, 2002:626-50.

\section{Benamer 2000}

Benamer HTS, Bone I. Cerebral venous thrombosis: anticoagulants or thrombolytic therapy?. Journal of Neurology, Neurosurgery, and Psychiatry 2000;69(4):427-30.

\section{Buccino 2003}

Buccino G, Scoditti U, Patteri I, Bertolino C, Mancia D. Neurological and cognitive long-term outcome in patients with cerebral venous sinus thrombosis. Acta Neurologica Scandinavica 2003;107(5):330-5.

\section{Canhão 2005a}

Canhão P, Ferro JM, Lindgren AG, Bousser MG, Stam J, Barinagarrementeria F (ISCVT Investigators). Causes and predictors of death in cerebral venous thrombosis. Stroke 2005;36(8):1720-5.

\section{Canhão 2005b}

Canhão P, Batista P, Falcao F. Lumbar puncture and dural sinus thrombosis - a causal or casual association?. Cerebrovascular Disease 2005;19(1):53-6.

\section{Ciccone 2004}

Ciccone A, Canhão P, Falcao F, Ferro JM, Sterzi R. Thrombolysis for cerebral vein and dural sinus thrombosis. Cochrane Database of Systematic Reviews 2004, Issue 1. [DOI: 10.1002/14651858.CD003693.pub2]

\section{Connor 2002}

Connor SEJ, Jarosz JM. Magnetic resonance imaging of cerebral venous sinus thrombosis. Clinical Radiology 2002;57(6):449-61.

\section{Coutinho 2011}

Coutinho J, de Bruijn SFTM, deVeber G, Stam J. Anticoagulation for cerebral venous sinus thrombosis. Cochrane Database of Systematic Reviews 2011, Issue 8. [DOI: 10.1002/14651858.CD002005.pub2]

\section{Cumurciuc 2005}

Cumurciuc R, Crassard I, Sarov M, Valade D, Bousser MG. Headache as the only neurological sign of cerebral venous thrombosis: a series of 17 cases. Journal of Neurology, Neurosurgery, and Psychiatry 2005;76(8):1084-7.

\section{De Bruijn 2001}

De Bruijn SF, De Hann RJ, Stam J. Clinical features and prognostic factors of cerebral venous thrombosis in a prospective series of 59 patients. Journal of Neurology, Neurosurgery, and Psychiatry 2001;70(1):105-8.

\section{DeVeber 2001}

DeVeber G, Andrew M, Adams C, Bjornson B, Booth F, Buckley DJ, et al. Cerebral venous thrombosis in children. New England Journal of Medicine 2001;345(6):417-23.

\section{Einhaupl 1994}

Einhaupl KM, Masuhr F. Cerebral venous and sinus thrombosis: an update. European Journal of Neurology 1994;1(2):109-26.

\section{Ferro 2003}

Ferro JM, Correia M, Rosas MJ, Pinto AN, Neves G. Seizures in cerebral vein and dural sinus thrombosis. Cerebrovascular Disease 2003;15(1-2):78-83.

\section{Heller 2003}

Heller C, Heinecke A, Junker R, Knofler R, Kosch A, Kurnik K, et al. Cerebral venous thrombosis in children: a multifactorial origin. Circulation 2003;108(11):1362-7.

\section{Higgins 2005}

Higgins JPT, Green S, (editors). Cochrane Handbook for Systematic Reviews of Interventions 4.2.4 [updated March 2005]. The Cochrane Collaboration, 2005. Available from www.cochrane-handbook.org.

\section{ILAE 1981}

International League Against Epilepsy. Commission on classification and terminology of the International League Against Epilepsy. Proposal for revised clinical and electroencephalographic classification of epileptic seizures. Epilepsia 1981;22(4):489-501.

\section{Lefebvre 2011}

Lefebvre C, Manheimer E, Glanville J. Chapter 6: Searching for studies. In: Higgins JPT, Green S, (editors). Cochrane Handbook for Systematic Reviews of Interventions Version 5.1.0 (updated March 2011). The Cochrane Collaboration, 2011. Available from http://handbook.cochrane.org/.

Masuhr 2004

Masuhr F, Mehraein S, Einhaupl K. Cerebral venous and sinus thrombosis. Journal of Neurology 2004;251(1):11-23.

\section{Preter 1996}

Preter M, Tzourio C, Ameri A, Bousser MG. Long-term prognosis in cerebral venous thrombosis. Follow-up of 77 patients. Stroke 1996;27(2):243-6.

\section{Stolz 2005}

Stolz E, Rahimi A, Gerriets T, Kraus J, Kaps M. Cerebral venous thrombosis: an all or nothing disease? Prognostic factors and long-term outcome. Clinical Neurology and Neurosurgery 2005;107(2):99-107. 


\section{Terazzi 2005}

Terazzi R, Mittino D, Ruda R, Cerrato P, Monaco F, Sciolla R, et al. Cerebral venous thrombosis: a retrospective multicentre study of 48 patients. Neurological Science 2005;25(6):311-5.

\section{Van den Bergh 2005}

Van den Bergh WM, Van der Schaaf I, Van Gijn J. The spectrum of presentations of venous infarction caused by deep cerebral vein thrombosis. Neurology 2005;65(2):192-6.

\section{References to other published versions of this review}

\section{Kwan 2005}

Kwan J, Guenther A, Kinton L. Antiepileptic drugs for the primary and secondary prevention of seizures after intracranial venous thrombosis. Cochrane Database of Systematic Reviews 2005, Issue 4. [DOI: 10.1002/14651858.CD005501]

\section{Kwan 2006}

Kwan J, Günther A. Antiepileptic drugs for the primary and secondary prevention of seizures after intracranial venous thrombosis. Cochrane Database of Systematic Reviews 2006, Issue 3. [DOI: 10.1002/14651858.CD005501.pub2]

\section{Price 2014}

Price M, Günther A, Kwan JSK. Antiepileptic drugs for the primary and secondary prevention of seizures after intracranial venous thrombosis. Cochrane Database of Systematic Reviews 2014, Issue 8. [DOI: 10.1002/14651858.CD005501.pub3]

\section{A P P E N D I CES}

\section{Appendix 1. Cochrane Epilepsy Group Specialized Register search strategy}

\#1 MeSH DESCRIPTOR Anticonvulsants Explode All WITH AD AE AG AN AI BL CF CS CH CL CT DU EC HI IM IP ME PK PD PO RE ST SD TU TO UR \#2 anticonvulsant* OR antiepilep* OR phenytoin OR valpro* OR carbamazepine OR ethosuximide OR phenobarbit* OR primidone \#3 MeSH DESCRIPTOR Phenobarbital Explode All WITH AD AE AG AA AN AI BL CF CS CH CL CT DU EC HI IM IP ME PK PD PO RE ST SD TU TO UR \#4 clobazam or clonazepam or diazepam or gabapentin or lamotrigine or levetiracetam or lorazapam or oxcarbazepine OR tiagabine or topiramate or vigabatrin or zonisamide

\#5 \#1 OR \#2 OR \#3 OR \#4

\#6 MeSH DESCRIPTOR Intracranial Embolism and Thrombosis Explode All WITH BL CF CI CL CO CN DI DH DT EC EM EN EP EH ET GE HI IM ME MI MO NU PS PA PP PC PX RA RI RT RH SU TH US UR VE VI

\#7 MeSH DESCRIPTOR Intracranial Thrombosis Explode All WITH BL CF CI CL CO CN DI DH DT EC EM EN EP EH ET GE HI IM ME MI MO NU PS PA PP PC PX RA RI RT RH SU TH US UR VE VI

\#8 MeSH DESCRIPTOR Sinus Thrombosis, Intracranial Explode All WITH BL CF CI CL CO CN DI DH DT EC EM EN EP EH ET GE HI IM ME MI MO NU PS PA PP PC PX RA RI RT RH SU TH US UR VE VI

\#9 MeSH DESCRIPTOR Intracranial Embolism Explode All WITH BL CF CI CL CO CN DI DH DT EC EM EN EP EH ET GE HI IM ME MI MO NU PS PA PP PC PX RA RI RT RH SU TH US UR VE VI

\#10 MeSH DESCRIPTOR Cerebral Veins Explode All WITH AB AH CH CY DE EM EN GD IM IN IR ME MI PS PA PH PP RE RA RI SE SU TR US UL VI \#11 MeSH DESCRIPTOR Cavernous Sinus Explode All WITH AB AH CH CY DE EM EN GD IM IN IR ME MI PS PA PH PP RE RA RI SE SU US UL VI \#12 MeSH DESCRIPTOR Cranial Sinuses Explode All WITH AB AH CH CY DE EM EN GD IM IN IR ME MI PS PA PH PP RE RA RI SE SU US UL VI \#13 MeSH DESCRIPTOR Dura Mater Explode All WITH AB AH BS CH CY DE EM EN GD IM IN ME MI PS PA PH PP RE RA RI SE SU TR US UL VI \#14 \#10 OR \#11 OR \#12 OR \#13

\#15 MeSH DESCRIPTOR Venous Thrombosis Explode All WITH BL CF CI CL CO CN DI DH DT EC EM EN EP EH ET GE HI IM ME MI MO NU PS PA PP PC PX RA RI RT RH SU TH US UR VE VI

\#16 MeSH DESCRIPTOR Thrombosis Explode All WITH BL CF CI CL CO CN DI DH DT EC EM EN EP EH ET GE HI IM ME MI MO NU PS PA PP PC PX RA RI RT RH SU TH US UR VE VI

\#17 MeSH DESCRIPTOR Thromboembolism Explode All WITH BL CF CI CL CO CN DI DH DT EC EM EN EP EH ET GE HI IM ME MI MO NU PS PA PP PC PX RA RI RT RH SU TH US UR VE VI

\#18 \#15 OR \#16 OR \#17

\#19 \#14 AND \#18

Antiepileptic drugs for the primary and secondary prevention of seizures after intracranial venous thrombosis (Review) 
\#20 (sinus* or sinovenous or cerebral venous or cerebral vein*) NEAR5 thrombo*

\#21 (cavernous or sagittal venous or sagittal vein* or sinus) NEAR5 thrombo*

\#22 cvdst or dct

\#23 \#6 OR \#7 OR \#8 OR \#9 OR \#19 OR \#20 OR \#21 OR \#22

\#24 \#5 AND \#23

\section{Appendix 2. CENTRAL (CRSO) search strategy}

\#1 (epilep* or seizure* or convulsion*):TI,AB,KY

\#2 (anticonvulsant* or antiepilep*):TI,AB,KY

\#3 MESH DESCRIPTOR Epilepsy EXPLODE ALL TREES WITH QUALIFIERS DT

\#4 MESH DESCRIPTOR Seizures EXPLODE ALL TREES WITH QUALIFIERS DT

\#5 MESH DESCRIPTOR Anticonvulsants EXPLODE ALL TREES

\#6 (phenytoin or valpro* or carbamazepine):TI,AB,KY

\#7 (ethosuximide or phenobarbit* or primidone):TI,AB,KY

\#8 MESH DESCRIPTOR Phenobarbital EXPLODE ALL TREES

\#9 (clobazam or clonazepam or diazepam):TI,AB,KY

\#10 (gabapentin or lamotrigine or levetiracetam):TI,AB,KY

\#11 (lorazapam or oxcarbazepine or tiagabine):TI,AB,KY

\#12 (topiramate or vigabatrin or zonisamide):TI,AB,KY

\#13 \#1 OR \#2 OR \#3 OR \#4 OR \#5 OR \#6 OR \#7 OR \#8 OR \#9 OR \#10 OR \#11 OR \#12

\#14 MESH DESCRIPTOR Intracranial Embolism and Thrombosis EXPLODE ALL TREES

\#15 MESH DESCRIPTOR Intracranial Thrombosis EXPLODE ALL TREES

\#16 MESH DESCRIPTOR Sinus Thrombosis, Intracranial EXPLODE ALL TREES

\#17 MESH DESCRIPTOR Intracranial Embolism EXPLODE ALL TREES

\#18 MESH DESCRIPTOR Cerebral Veins EXPLODE ALL TREES

\#19 MESH DESCRIPTOR Cavernous Sinus EXPLODE ALL TREES

\#20 MESH DESCRIPTOR Cranial Sinuses EXPLODE ALL TREES

\#21 MESH DESCRIPTOR Dura Mater EXPLODE ALL TREES

\#22 \#18 OR \#19 OR \#20 OR \#21

\#23 MESH DESCRIPTOR Venous Thrombosis EXPLODE ALL TREES

\#24 MESH DESCRIPTOR Thrombosis EXPLODE ALL TREES

\#25 MESH DESCRIPTOR Thromboembolism EXPLODE ALL TREES

\#26 \#23 OR \#24 OR \#25

\#27 \#22 AND \#26

\#28 ((sinus* or sinovenous or cerebral venous or cerebral vein*) near5 thrombo $\left.{ }^{\star}\right): \mathrm{TI}, \mathrm{AB}, \mathrm{KY}$

\#29 ((cavernous or sagittal venous or sagittal vein* or sinus) near5 thrombo*):TI,AB,KY 
\#30 (cvdst or dct):TI,AB, KY

\#31 \#14 OR \#15 OR \#16 OR \#17 OR \#27 OR \#28 OR \#29 OR \#30

\#32 \#13 AND \#31

\#33 31/08/2013 TO 31/05/2015:DL

\#34 \#32 AND \#33

\section{Appendix 3. MEDLINE search strategy}

The following search strategy is based on the Cochrane Highly Sensitive Search Strategy for identifying randomised trials (Lefebvre 2011).

1. randomized controlled trial.pt.

2. controlled clinical trial.pt.

3. randomi?ed.ab.

4. placebo.ab.

5. clinical trials as topic.sh.

6. randomly.ab.

7. trial.ti.

8. 1 or 2 or 3 or 4 or 5 or 6 or 7

9. exp animals/ not humans.sh.

10. 8 not 9

11. exp Epilepsy/

12. exp Seizures/

13. (epilep\$ or seizure\$ or convuls\$).tw.

14. anticonvulsant\$.tw.

15. exp Anticonvulsants/

16. antiepilep\$.tw.

17. phenytoin.tw.

18. valpro\$.tw.

19. carbamazepine.tw.

20. ethosuximide.tw.

21. phenobarbit\$.tw.

22. exp Phenobarbital/

23. primidone.tw.

24. or $/ 11-23$

25. "Intracranial Embolism and Thrombosis"/

26. Intracranial Thrombosis/

27. exp Sinus Thrombosis, Intracranial/

28. Intracranial Embolism/ 
29. Cerebral Veins/

30. Cavernous Sinus/

31. Cranial Sinuses/

32. exp Dura Mater/

33. 29 or 30 or 31 or 32

34. Venous Thrombosis/

35. Thrombosis/

36. Thromboembolism/

37.34 or 35 or 36

38. 33 and 37

39. ((sinus\$ or sinovenous or cerebral venous or cerebral vein $\$$ or cavernous or sagittal venous or sagittal vein $\$$ or sinus) adj5 thrombo\$).tw.

40. (cvdst or cvt).tw.

41. 25 or 26 or 27 or 28 or 38 or 39 or 40

42. 10 and 24 and 41

43. limit 42 to ed $=20130822-20150420$

Earlier versions of this review used the following search strategy. We received guidance from the Cochrane Stroke Group for the stroke section (lines 39 to 54) of the search strategy for MEDLINE. The epilepsy and intervention sections of the search strategy (lines 22 to 36) were standard for the Cochrane Epilepsy Group. Lines 1 to 21 are drawn from the Cochrane highly sensitive search strategy for identifying randomised trials in MEDLINE as set out in Appendix 5b of the Cochrane Handbook for Systematic Reviews of Interventions (version 4.2.4, updated March 2005) (Higgins 2005).

1. randomized controlled trial.pt.

2. controlled clinical trial.pt.

3. exp Randomized Controlled Trials/

4. exp Random Allocation/

5. exp Double-Blind Method/

6. exp Single-Blind Method/

7. 1 or 2 or 3 or 4 or 5 or 6

8. (animals not humans).sh.

\section{7 not 8}

10. clinical trial.pt.

11. Clinical Trial/

12. (clin\$ adj trial\$).ab,ti.

13. ((singl\$ or doubl\$ or trebl\$ or tripl\$) adj (blind\$ or mask\$)).ab,ti.

\section{4. exp PLACEBOS/}

15. placebo\$.ab,ti.

16. random\$.ab,ti.

\section{7. exp Research Design/}

Antiepileptic drugs for the primary and secondary prevention of seizures after intracranial venous thrombosis (Review) 
18.10 or 11 or 12 or 13 or 14 or 15 or 16 or 17

19. (animals not humans).sh.

20. 18 not 19

21.9 or 20

22. epilep\$.tw.

23. exp EPILEPSY/

24. seizure\$.tw. [

25. exp SEIZURES/

26. convulsion\$.tw.

27. anticonvulsant\$.tw.

28. exp ANTICONVULSANTS/

29. antiepilep\$.tw.

30. phenytoin.tw.

31. valpro\$.tw.

32. carbamazepine.tw.

33. ethosuximide.tw.

34. phenobarbit\$.tw. [

35. exp PHENOBARBITAL/

36. primidone.tw.]

37.22 or 23 or 24 or 25 or 26 or 27 or 28 or 29 or 30 or 31 or 32 or 33 or 34 or 35 or 36

38. 21 and 37

39. "Intracranial Embolism and Thrombosis"/

40. Intracranial Thrombosis/

41. exp Sinus Thrombosis, Intracranial/

42. Intracranial Embolism/

43. Cerebral Veins/

44. Cavernous Sinus/

45. Cranial Sinuses/

46. exp Dura Mater/

47.43 or 44 or 45 or 46

48. Venous Thrombosis/

49. THROMBOSIS/

50. THROMBOEMBOLISM/

51.48 or 49 or 50

52. 47 and 51

Antiepileptic drugs for the primary and secondary prevention of seizures after intracranial venous thrombosis (Review) 
53. ((sinus\$ or sinovenous or cerebral venous or cerebral vein\$ or cavernous or sagittal venous or sagittal vein\$ or sinus) adj5 thrombo $\$) . t w$.

54. (cvdst or cvt).tw.

55.39 or 40 or 41 or 42 or 52 or 53 or 54

56.38 and 55

Appendix 4. Cochrane Stroke Group Specialized Register search strategy

Search method: 1

Stage: Not specified

Disease: Not specified

Condition: Seizures

Intervention type: Pharmacology

Intervention code: Not specified

WHAT'S NEW

\begin{tabular}{lll}
\hline Date & Event & Description \\
\hline 20 April 2015 & $\begin{array}{l}\text { New citation required but conclusions } \\
\text { have not changed }\end{array}$ & No new trials identified; conclusions are unchanged. \\
\hline 20 April 2015 & New search has been performed & Searches updated 20 April 2015. \\
\hline
\end{tabular}

\section{H I S T O R Y}

Protocol first published: Issue 4, 2005

Review first published: Issue 3, 2006

\begin{tabular}{lll}
\hline Date & Event & Description \\
\hline 12 August 2013 & New search has been performed & Searches updated 12 August 2013; no new trials identified. \\
\hline 12 August 2013 & $\begin{array}{l}\text { New citation required but conclusions } \\
\text { have not changed }\end{array}$ & Conclusions remain the same. \\
\hline 31 August 2011 & New search has been performed & Searches updated 31 August 2011; no new trials identified. \\
\hline 17 March 2010 & Amended & Co-author's contact details updated. \\
\hline 6 January 2010 & New search has been performed & Searches updated 6 January 2010; no new trials identified. \\
\hline 16 September 2008 & Amended & Converted to new review format. \\
\hline
\end{tabular}

\section{CONTRIBUTIONS OF AUTHORS}

Dr Joseph Kwan and Dr Albrecht Guenther screened the studies and wrote the original text of the review. Dr Michelle Price screened the studies and added any updated text for 2014 update. 


\section{DECLARATIONS OF INTEREST}

None known.

\section{SOURCES OF SUPPORT}

\section{Internal sources}

- University of Southampton, UK.

\section{External sources}

- National Institute for Health Research (NIHR), UK.

This review was supported by the National Institute for Health Research, via Cochrane Infrastructure funding to the Epilepsy Group. The views and opinions expressed herein are those of the authors and do not necessarily reflect those of the Systematic Reviews Programme, NIHR, National Health Service or the Department of Health.

\section{INDEX TERMS}

\section{Medical Subject Headings (MeSH)}

Anticonvulsants [*therapeutic use]; Intracranial Thrombosis [ ${ }^{*}$ complications]; Primary Prevention; Secondary Prevention; Seizures [ ${ }^{\star}$ etiology] [prevention \& control]; Venous Thrombosis [ ${ }^{\star}$ complications]

\section{MeSH check words}

Humans 